\title{
Influencing Factors of University Students' Use of Social Network Sites: An Empirical Analysis in China
}

\author{
https://doi.org/10.3991/ijet.v13i03.8380 \\ Liqiong Liu \\ Wuhan University, Wuhan Business University, Wuhan, China \\ Liyi Zhang \\ Wuhan University, Wuhan, China \\ Pinghao $\mathrm{Ye}^{(\varpi)}$ \\ Wuhan Business University, Wuhan, China \\ Yezigege1977@163.com \\ Qihua Liu \\ Jiangxi University of Finance and Economics, Nanchang, China
}

\begin{abstract}
This paper explores the influencing factors of Chinese university students in accepting and using social networking sites (SNS) to propose measures and recommendations that can guide and help these students correctly use SNS. In addition, this paper aims to provide theoretical support in increasing user loyalty for the SNS service providers and attract new users. The correlation and multiple regression analyses showed that perceived value, enjoyment, and influence positively influence the intention of individuals to use SNS.
\end{abstract}

Keywords-Social Networking, user behavior, Case studies

\section{Introduction}

Social networking sites (SNS) combine information technology with social network, serving as an Internet application service that helps people establish a social network online. In addition, SNS carries information, providing its users with a platform in which they can display their personalities, create personal files, publish diaries, and upload pictures. Facebook and Google+ have not entered the Chinese market, but the competition between SNS service providers, such as Renren, Kaixin, and $\mathrm{QQ}$, is strong because of the overlapping users and market share competition. A statistical report on the development of the Internet in China, which was published by China Internet Network Information Center in January 2016, shows that the use rates of QQ Space and Weibo by netizens are 65.1 per cent and 33.5 per cent, respectively. The total number of SNS users in China has exceeded 400 million. Thus, SNS service providers have focused on attracting additional users to continue the use of SNS net- 
work and developed their user values by fully utilizing the social attributes of the SNS platforms.

This paper establishes the conceptual model of using SNS in the contexts of user perceived value and social influence. Moreover, this paper explores the influence of value and entertainment factors on the acceptance of SNS to provide SNS service providers and relevant practitioners with reference and guidance and to promote the healthy and continual development of the SNS service industry.

\section{$2 \quad$ Literature review}

SNS has become an important channel for people to obtain and share information, establish relationships, and be entertained. [1]pointed out that in the context of social computing, the existing social attributes of SNS have been deeply integrated into individual life and that the acceptance and use of SNS should be observed from crossdisciplinary and multi-angle perspective because traditional information system models cannot interpret accurately these data. SNS has become the front research field of computer science, management science, behavioral science, sociology, and psychology. Therefore, based on the background of practice and theory, the present research focuses on the value perception of users toward SNS websites and the social influence between the users from the point of sociology to study the factors that influence the users in accepting SNS. The findings provide useful reference and guidance to SNS service providers in building and training user loyalty and increasing website stickiness. The findings of this study also enrich the research related with SNS service operation and management to examine and observe the new Internet phenomenon of SNS from a full and multi-angle perspective.

The analysis of the factors that can influence the users in accepting and using SNS helps in the discovery of behavioral motives of the users. Moreover, such analysis can accurately identify the behavior rules of SNS users and help in the analysis, guidance, and monitoring of network public opinion events, which have great significance for further research on information communication rules. All research related to SNS service is mainly focused on the analysis and research of SNS user features and user privacy protection. SNS service research pays minimal attention to university students, who are the most active SNS users, and on the factors that can influence their SNS acceptance.

The field theory of social psychologist Levin and the social cognitive theory of social psychologist Bandura stipulate that human behavior depends on the influence of the environment in which they exist. The factors that can influence the intention of individuals to use SNS can be divided into two categories. One is the external environmental factors, including subjective norm, social identity, trust, critical majority, collective norm, and network externality, which reflect social influence. The other is the self-factor of the users, such as their motive, cognition, population variables, attitude, personality, and attitude. The research on SNS use motive has achieved rich results although the motives of use summarized by these studies vary to a certain 
extent. Most researchers mention three categories of factors that can influence the intention of users to employ SNS: social exchange, information, and entertainment.

\subsection{Influencing factors of social environment}

The effects of social factors, such as subjective norm [2], collective norm [3] [4], social identity[5], and trust[2] [6,7], on users' acceptance of SNS have been confirmed. In addition, the effects of the factors that reflect social demonstration effect and bandwagon effect (e.g., critical majority, perceived popularity, network externality, and social influence) on SNS acceptance have received attention from some scholars. This case shows that the social influence from significant others or the general public greatly influences the users' acceptance of SNS.

Scholars have analyzed the influential factors of the use of SNS from the motives of users who accept SNS. These motives include social, information, and entertainment motives. The theory of social influence specifies that social environmental factors influence the behavior of human beings. These factors can be divided into information and normative influences. The collective intention to use an SNS is determined by both subjective norm and social identity [8]. The motives of users in using SNS and determined that practicality, leisure, and entertainment are important influencing factors[9]. Facebook users and analyzed the factors that can influence their intention in using SNS $[3,10]$. The researchers determined that social presence significantly influences the intention of individuals in using SNS. [11] investigated the factors that can influence the acceptance and use of SNS by university students and discovered that the cultural fact or of individualism-collectivism positively influences the pervasive adoption of SNS. In particular, the students with individualistic cultures have significant levels of engagement.

\subsection{Influencing factors of personality features}

The technology acceptance model (TAM) introduced by Davis Fred explains that a user's intention of adopting a new information technology or the behavior of practical use is influenced by his/her cognitive factors (i.e., perceived usefulness and perceived ease of use) and emotional factors (i.e., attitude of use) [12]. Scholars have adopted TAM to study the behavior of users in SNS adoption [5]. Perceived orientation and perceived encouragement are significant constructs that affect the actual use of SNS [13]. Usefulness, number of peers, and enjoyment are the most influential factors in customer's continued use of SNS.

The five-factor model of personality (FFM) shows that the five basic dimensions of extroversion, conscientiousness, emotional stability, agreeableness, and openness to experience can fully describe the personality features of individuals. The influencing factors of the adoption behavior of SNS users on the basis of FFM and found that people with high extroversion and low conscientiousness are apt to the adoption of SNS[14]. Moreover, loneliness and shyness affect adoption. The individuals with high social loneliness and high shyness are unlikely to adopt SNS. [15] combined the FFM model to study the personality factors that influence university students in using 
SNS and found that those with high levels of openness and loneliness have numerous friends, but they spend a huge amount of time online. The students with high loneliness, high shyness, and low stimulation are unlikely to use SNS[16]. However, [15] clarified that the negative influence of loneliness on the use of SNS is insignificant. That non-SNS users have a high level of covert narcissism[7]. Self-esteem is negatively correlated with the Facebook friends of SNS users[4, 17]. [18] used social comparison theory to conduct a comparative study on the acceptance behavior of SNS users and found that those with a high level of self-perception rarely conduct negative social comparison because this phenomenon is significant with unhappy individuals. That extroversion can influence the use of SNS by influencing the perceived enjoyment of the users [19].

Thus, extroversion, shyness, loneliness, and narcissism are personality features that can significantly influence social exchange in reality as well as the adoption of SNS by users.

\subsection{Influencing factors of population statistics}

Some studies proved that demographic variables, such as sex and age, significantly influence the intention of SNS use. The factors that influence the acceptance and use of SNS from the three dimensions of information, establishing friendships, and making connections[20]. Consequently, the researchers determined that the use of SNS varies among users in terms of their sex and age. Sex significantly influences SNS adoption and that females are more apt to use SNS than males[21]. The relationship status greatly affects the Facebook activity of males but only slightly influences those of females[22]. [6] performed a large-scale investigation and analysis on young students at the early stage of SNS and found that sex, nationality/race, and education background of parents are related to SNS use. Entertainment is an important factor that influences the satisfaction of males in using SNS[23]; moreover, relationship maintenance is an important factor that influences the satisfaction of females in using SNS. The age is negatively correlated with the adoption of SNS [16], that is, people of older age are unlikely to own SNS accounts.

Adoption behavior, such as oral spreading behavior, is understood from varying perspectives with the development of socialized computer technology. This circumstance implies that recommendation behavior can be regarded as an important part of the dimension of continuous use behavior. Research shows that users who continuously use a product or service will continue to do so and will also attract additional users to use the product or service by spreading its good reputation.

\section{Research model and hypothesis}

The research model for the influence on the intention of university students in using SNS has been constructed based on the conclusions of the above document research and the characteristics of university students in using SNS. These characteristics include the three variables of perceived value, perceived enjoyment, and per- 
ceived influence, as illustrated by Figure 1. The development of the theoretical model and hypotheses are discussed in detail below.

\subsection{Perceived value}

Perceived value is the subjective judgment of the utility of a product or service formed based on perceived benefits and sacrifices that are comprehensively measured by users. University students are individuals with reason, and their perceived judgment of service value influences their attitude and behavior toward the utility of the service. Users highly intend to use a service when it can bring higher value to them than the other similar services. Users of online travel and video service and determined that their perceived value has a significant positive correlation with their loyalty[24]. The perceived value is the effective predictive variable that influences the adoption of service by users of the two behaviors of online purchase[25]. Users intend to realize oral spreading and recommend a service to their friends when the perceived utility value and perceived enjoyment of the service are increased[26]. [27] looked into 613 bank users and found that their perceived utility value and enjoyment value positively affect their adoption behavior. Thus, the following hypothesis is formulated.

H1. Perceived value positively affects consumer intention to use SNS.

\subsection{Perceived enjoyment}

Users who adopt tools (e.g., SNS) and enjoyment information services pay attention to the tool benefits that can be obtained, the emotional experience of active enjoyment, and the enjoyment benefits of good user experience. Perceived enjoyment from the SNS is not mistaken as the net benefit in system use[28]. Perceived enjoyment is the extent to which the use of an SNS is perceived to be enjoyable, apart from any associated performance consequences [29]. The users who enjoy a web system view their interactions with the system positively and form a high behavior intention to use it[30]. Users mainly use SNS because of their perceived fun and entertainment in communicating with their families and friends, exchanging information, sharing pictures and videos, and participating in collective affairs through the platform[31]. Perceived enjoyment and playfulness as well as the attitude of use are the major emotional factors that influence users' adoption of SNS. The following hypothesis is formulated.

H2. Perceived delight positively affects consumer intention to use SNS.

\subsection{Perceived influence}

The theory of social influence points out that human behavior is influenced by social environmental factors. From the perspective of influence process, social influence can be classified into three categories, namely, submission, internalization, and identity. Contrarily, in the context of influence types, social influence can be classified into information and normative influences. Individuals using a product and service are 
simultaneously present in multiple social organizations and groups, and their behavior of use is influenced by the social groups in which they are part of[32]. Moreover, the users intentionally downsize their range of choices to maintain the mode of use of the product or service that is acceptable to the group in which they exist because of social influence and the action of submission pressure. User loyalty is influenced by the selffactors of users and the pressure of social norms, particularly when their purchase or use decisions are sensitive to social influence [33]. [3] investigated Facebook users from the point of social influence to explore the effect of subjective norm, collective norm, and social identity on the intention of SNS use. The researchers found that social influence significantly affects users' intention of SNS use. The motive of university students in using SNS and found that SNS users can receive benefit from the number of SNS users[34]. In addition, these researchers determined that the users' SNS can be extended, and the critical majority is a critical factor that can influence the use of new technology.

Thus, the influence induced by significant others (i.e., subjective/collective norm and social identity) or the general public (i.e., critical majority, perceived popularity, and network externality) can greatly influence individual use of SNS and similar social media. Therefore, the following hypothesis is proposed.

H3. Perceived influence positively affects consumer's intention to use SNS.

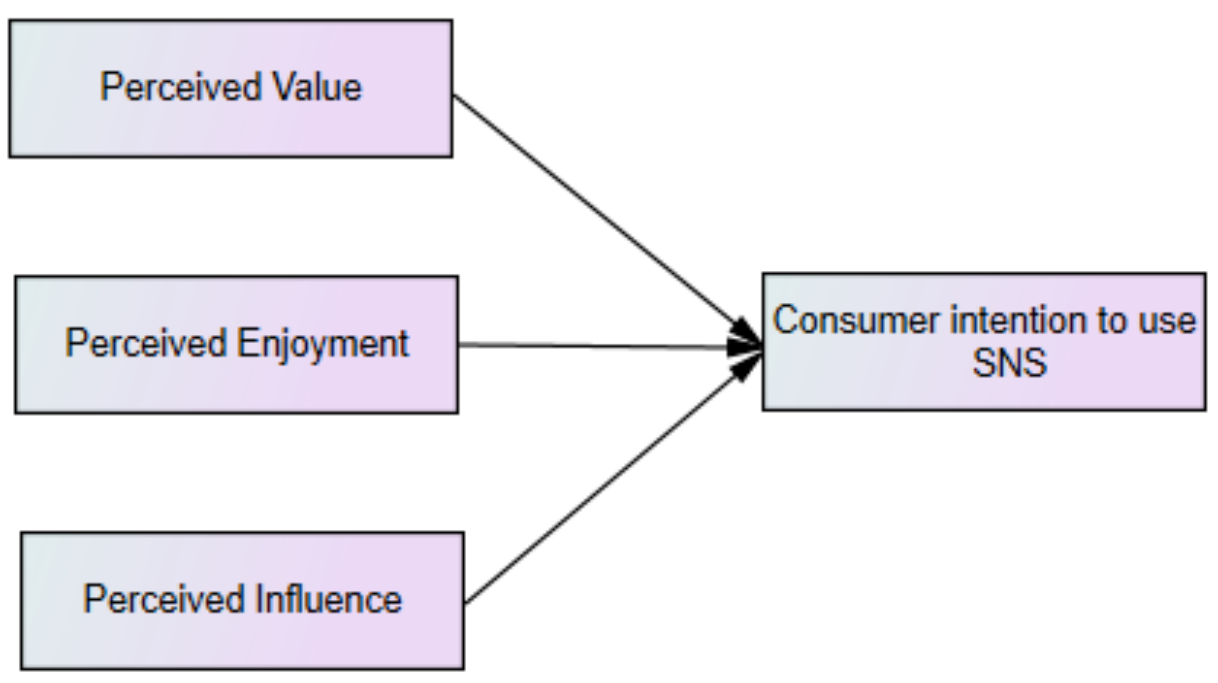

Fig. 1. Research Model

\section{$4 \quad$ Methodology}

This research combined existing research achievements and set the survey scale of exploratory factor analysis for the intention of SNS acceptance through a predictive experimental survey. Thus, the questionnaire for the exploratory factor analysis was developed, and the survey questions referred to existing mature survey scales. 
The questionnaire has two parts. The first part contains the background of users, including their age, profession, and SNS usage (i.e., frequency of use and platforms). The second part is the cognition of SNS by university students and their intention of acceptance. This part includes perceived value, enjoyment, and influence, as well as the intention of acceptance.

University students were considered the survey objects, and an online questionnaire method was adopted. Prior to the official commencement of the survey, the questionnaire was tested by 50 students. Considering the result of this pretest, the unclear questions were deleted and revised. In the actual survey, the questionnaire was distributed among students of different grades and majors, and 305 questionnaire papers were returned.

SPSS 23.0 analytical software was employed for the statistics of the survey data and Amos 23.0 for the confirmatory analysis of the hypothesis of the research model. The results were analyzed using structural equation modeling in Amos 23.

\section{$5 \quad$ Variable measurement}

\subsection{Independent variables}

The independent variables were based on factors derived from frontier research (see table I) . The questions were modified to fit the context of SNS. Each question was measured by five-point likert scale. For instance, "1" denoted as strongly agree, " 2 " denoted as agree, " 3 " denoted as neutral, "4" denoted as disagree, "5" denoted as strongly disagree. Hence, in this research, a total of 12 survey items for 4 constructs in the questionnaire actually come from the prior empirical research. Table I shows the sources of where the questions were adopted from and the number of items used in representation of the independent variables.

\subsection{Dependent variable}

A list of intention to use SNS was adapted from [35] and [36] for the purpose of measurement in the adoption of SNS in China. A total of 4 questions were used to measure the dependent variable. The consumer intention to use SNS was measured using five-point Likert scale where 1-strongly agree, 2-agree, 3-neutral, 4-disagree and 5-strongly disagree.

Table 1. Constructs and their sources

\begin{tabular}{|l|c|l|}
\hline \multicolumn{1}{|c|}{ Constructs } & Number of items & \multicolumn{1}{c|}{ References } \\
\hline Perceived Value & 4 & {$[12],[37],[38],[39],[17],[40]$} \\
\hline Perceived Enjoyment & 2 & {$[41],[2],[42],[43],[44],[45]$} \\
\hline Perceived Influence & 2 & {$[46]$} \\
\hline Intention to use SNS & 4 & {$[35],[36]$} \\
\hline
\end{tabular}




\section{Data analysis}

\subsection{Profile of respondents}

Among the survey objects, 23.93 per cent were males and 76.07 per cent were females. With regard to the distribution of majors, 68.52 per cent of the users are taking liberal arts, 28.52 per cent are majoring in science, and 2.95 per cent are engineering students. Among this population, micro-blog is the most commonly used SNS at 87.21 per cent, followed by post bar at 58.03 per cent and QQ at 29.84 per cent. About 81.3 per cent of the users use SNS an hour per day on the average; 82.3 per cent of the entire sample is freshmen, whereas only 17.05 per cent is sophomore. Table II presents the demographic profile of the surveyed respondents.

Table 2. Demographic profile of the respondents

\begin{tabular}{|l|l|c|c|}
\hline \multicolumn{1}{|c|}{ Variables } & & Frequency & Per cent (\%) \\
\hline \multirow{4}{*}{ Gender } & Male & 73 & 23.93 \\
\hline \multirow{4}{*}{ Academic Classification } & Female & 232 & 76.07 \\
\hline \multirow{5}{*}{ Grade } & Liberal arts & 209 & 68.52 \\
\cline { 2 - 4 } & Science & 87 & 28.52 \\
\cline { 2 - 4 } & Engineering & 9 & 2.95 \\
\hline \multirow{5}{*}{ Use of SNS } & Freshman & 251 & 82.3 \\
\cline { 2 - 4 } & Sophomore & 2 & 17.05 \\
\cline { 2 - 4 } & Junior & 61 & 0.65 \\
\hline \multirow{5}{*}{ Length of each use SNS } & Blogs & 177 & 20 \\
\cline { 2 - 4 } & Post bar & 85 & 58.03 \\
\cline { 2 - 4 } & Forum & 266 & 27.87 \\
\cline { 2 - 4 } & Micro-blog & 100 & 87.21 \\
\cline { 2 - 4 } & QQ & 98 & 29.84 \\
\hline & 20 minutes & 50 & 32.79 \\
\cline { 2 - 4 } & Half an hour & 19 & 16.39 \\
\cline { 2 - 4 } & 1 hour & 38 & 6.23 \\
\cline { 2 - 4 } & 2 hours & & 12.46 \\
\cline { 2 - 4 } & 2 hours or more & & \\
\hline
\end{tabular}

\subsection{Scale reliability and factor analysis}

SPSS 23.0 was used for the reliability check of the questionnaire, and the questionnaire scale was internally verified with Cronbach coefficient. The inspection showed that $a$ (reliability coefficient) is 0.811 , and the respective inspection results of the reliability of every potential variable is larger than 0.8 . The variables show good internal consistency, that is, the reliability of the questionnaire is acceptable [47].

Construct validity measures "the degree to which a scale measures what it intends to measure" [48]. In this study, this degree was assessed by factor analysis. SPSS 23.0 was first used for Bartlett and KMO measurement. The analytical results showed the Bartlett spherical check of 12 indexes $x^{2}=852.198$ ( $p$-value $\left.<0.001\right)$. These indexes reflect that the information is overlapping to a certain extent and that factor analysis is necessary. KMO check was used to survey the partial correlation of the variables. The 
value varies between $0-1$. The correlation between the variables is strong, and the effect of factor analysis is satisfactory when the KMO statistic is close to 1 . The research $\mathrm{KMO}=0.831$ is larger than 0.5 , implying that it is suitable for factor analysis [49].

Table III shows the 12 items sorted and clustered into four components, namely, Factor 1: perceived value, Factor 2: perceived enjoyment, Factor 3: perceived influence, and Factor 4: intention to use SNS. The Eigen values of the perceived value, enjoyment, and influence are 2.260, 1.538, and 1.080, respectively. The Eigen value for each factor is greater than 1.0, which implies that each factor can explain more variance than a single variable. Principal component analysis was conducted to take common factors for factor analysis, and 12 common factors were extracted from the 12 indexes. The cumulative percentage of variance explained by four factors is 60.049 per cent, suggesting that more than 60 per cent of the common variance shared by 12 items can be accounted or explained by the four factors. Therefore, construct validity was established.

Table 3. Factor analysis

\begin{tabular}{|c|c|c|c|c|}
\hline Variable & Scale items & Factor loading & Percentage of variance & Eigen values \\
\hline \multirow{4}{*}{ Perceived value } & $\begin{array}{l}\text { The use of SNS allows me } \\
\text { to obtain the information } \\
\text { resources I need. }\end{array}$ & 0.532 & 38.228 & 2.260 \\
\hline & $\begin{array}{l}\text { The use of SNS makes my } \\
\text { work easier. }\end{array}$ & 0.652 & & \\
\hline & $\begin{array}{l}\text { The use of SNS allows me } \\
\text { to gain additional friends. }\end{array}$ & 0.649 & & \\
\hline & $\begin{array}{l}\text { The use of SNS improves } \\
\text { my influence. }\end{array}$ & 0.528 & & \\
\hline \multirow[t]{2}{*}{ Perceived enjoyment } & $\begin{array}{l}\text { The use of SNS increases } \\
\text { my communication with } \\
\text { friends. }\end{array}$ & 0.801 & 51.045 & 1.538 \\
\hline & $\begin{array}{l}\text { The use of SNS increases } \\
\text { my interest in learning. }\end{array}$ & 0.650 & & \\
\hline \multirow{2}{*}{ Perceived influence } & $\begin{array}{l}\text { SNS with a recommenda- } \\
\text { tion system influences my } \\
\text { use. }\end{array}$ & 0.900 & 60.049 & 1.080 \\
\hline & $\begin{array}{l}\text { SNS with good image and } \\
\text { experience influences my } \\
\text { use. }\end{array}$ & 0.693 & & \\
\hline Intention to use SNS & $\begin{array}{l}\text { I feel relaxed after I use } \\
\text { SNS. } \\
\text { The use of SNS enhances } \\
\text { my relationship with } \\
\text { friends. } \\
\text { The use of SNS upgrades } \\
\text { my personal value. } \\
\text { I recommend the use of } \\
\text { SNS to others. }\end{array}$ & $\begin{array}{l}0.794 \\
0.680 \\
0.609 \\
0.536\end{array}$ & 19.392 & 2.327 \\
\hline
\end{tabular}




\subsection{Correlation analysis}

Correlation analysis is the analysis of two or more variable elements with correlation to measure the correlation degree of two variables. In this study, the correlation analysis of four factors (Table IV) showed that the associated pairs of variables are significant at level 0.01. However, all the hypothesized relationships developed are statistically significant at level $p<0.01$. Perceived value $(r=0.567, p<0.01)$, perceived enjoyment $(r=0.335, p<0.01)$, and perceived influence $(r=0.463, p<0.01)$ are correlated with consumer intention to use SNS significantly and positively.

Table 4. Pearson correlation coefficient

\begin{tabular}{|l|c|c|c|c|}
\hline & $\begin{array}{c}\text { Intention to use } \\
\text { SNS }\end{array}$ & Perceived Value & $\begin{array}{c}\text { Perceived Enjoy- } \\
\text { ment }\end{array}$ & $\begin{array}{c}\text { Perceived Influ- } \\
\text { ence }\end{array}$ \\
\hline Intention to use SNS & 1 & $0.567^{* *}$ & $0.335^{* *}$ & $0.463^{* *}$ \\
\hline Perceived Value & $0.567^{* *}$ & 1 & $0.370^{* *}$ & $0.530^{* *}$ \\
\hline Perceived Enjoyment & $0.335^{* *}$ & $0.370^{* *}$ & 1 & $0.229^{* *}$ \\
\hline Perceived Influence & $0.463^{* *}$ & $0.530^{* *}$ & $0.229^{* *}$ & 1 \\
\hline
\end{tabular}

Note: $* *$ Correlation significant at the level 0.01 (two-tailed)

\subsection{Multiple regression analysis}

Multiple regression analysis was applied to test the research hypotheses. Table V illustrates the results. Durbin-Watson (DW) statistic was used for testing autocorrelation. In general, a DW statistic should range from 1.5 to 2.5 [50]. The DW value in this research is 1.792 , which is close to Description 2.The DW value does not have any independent correlation.

The existence of multiple co-linearity should be determined in multiple regression analysis. Multiple co-linearity can be diagnosed using various methods. The commonly used method is the variation inflation factors (VIF) proposed by [51]. When VIF $\geq 5$ or $\mathrm{VIF} \geq 10$, the co-linearity between independent variables is serious. A high VIF value implies a strong co-linearity between the independent variables. In this research, the VIF values of various independent variables are smaller than 5; thus, multiple co-linearity exists [52].

The $F$-statistics produced $(F=60.018)$ was significant $(p<0.001)$, implying that there is a positive and statistically significant association between the influence factors and the intention to use SNS, The coefficient of determination $R^{2}$ was 37.4 per cent. Thus, the influence factors can significantly account for 37.4 per cent in the college student intention to use SNS.

The regression analysis showed that the regression coefficient of perceived value is 0.509 with a significance of 0.000 , which is smaller than 0.05 . Thus, the regression coefficient is significant. This finding confirms that perceived value significantly positively affects the intention to use SNS. The regression coefficient of the independent variable perceived enjoyment is 0.106 with a significance of 0.006 , which is smaller than 0.05 ; thus, the regression coefficient is significant. This result verifies that perceived enjoyment significantly positively affects the intention to use SNS. The regression coefficient of the independent variable perceived influence is 0.093 with a 
significance of 0.005 , which is smaller than 0.05 . Thus, the regression coefficient is significant, and perceived influence has a significant positive effect on the intention to use SNS. Therefore, $H 1, H 2$, and $H 3$ are supported.

Table 5. Multiple regression analysis

\begin{tabular}{|l|l|l|l|l|l|}
\hline \multicolumn{1}{|c|}{ Predictor variable } & \multicolumn{1}{c|}{$\boldsymbol{\beta}$} & \multicolumn{1}{c|}{$\boldsymbol{t}$-value } & \multicolumn{1}{c|}{ Sig } & \multicolumn{1}{c|}{ Tolerance } & \multicolumn{1}{c|}{ VIF } \\
\hline Perceived value & 0.509 & 9.978 & 0.000 & 0.827 & 1.209 \\
\hline Perceived Enjoyment & 0.106 & 2.788 & 0.006 & 0.868 & 1.152 \\
\hline Perceived Influence & 0.093 & 2.798 & 0.005 & 0.932 & 1.073 \\
\hline
\end{tabular}

Notes: Overall model $\mathrm{F}=60.018 ; p<0.001 ; \mathrm{R}^{2}=0.374$; adjusted $\mathrm{R}^{2}=0.368$; Durbin-Watson test $=1.792$

\section{$7 \quad$ Discussion and conclusion}

Perceived value significantly positively affects the SNS use of university students. Many studies have determined that perceived value is an important predictor in explaining the intention to use SNS $[36,53]$. The present study supports these findings and show that a strong positive relationship exists between perceived value and the consumers' intention to use SNS. The students believe that their use of SNS upgrades their performance when the SNS brings high value to their study and life; thus, their intention to use SNS is strengthened. The cognition that SNS upgrades individual performance influences the initiative of university students to use SNS, which allows them to actively take part in SNS activities and pay increased attention to SNS development. However, this cognition is good for the initiative of university students to recommend SNS to their friends, thereby improving the broad promotion of SNS.

Perceived enjoyment induces a significant positive effect on the SNS use of university students. The result in this study is consistent with prior studies [31, 41, 54]. Enjoyment is one of the most important features of SNS, which provides entertainment and relaxation experience to users, thereby influencing them to continually use the service[55]. Users are motivated to use SNS to satisfy their enjoyment needs. The advantage of SNS in helping users in entertainment and leisure is reflected in two aspects. First, SNS has a large amount of information for entertainment and leisure from various sources, such as pictures and jokes, which can be originally created by users or shared by other websites. Second, SNS development incorporates further third-party applications, which enrich leisure and entertainment and satisfy the entertainment needs of users.

Perceived influence significantly positively influences university students when using SNS, which makes the determinant parallel with previous studies [4, 8]. The concept of perceived influence can assist the success of intention to use SNS. SNS users maintain contact with other members owing to their common interests and topics. A user who has established identity with his/her own social circle is influenced by the circle. This research determined that the individuals who have been engaging in an activity intend to participate in such activity repeatedly. Moreover, the critical majority of users who repeatedly participate in the SNS activities create a positive influence on the attitude and behaviors of new users. 
Thus, SNS should continuously improve its service quality, increase its service content, continuously optimize its structural layout and navigation design, simplify its user operation, and upgrade the perceived value of its potential users. In addition, SNS should pay attention to the experience of its users, increase its entertainment application and fun content, increase the perceived enjoyment of users in using it, enhance its website advertising force, increase the incentive rate for old users who invite new users, fully utilize its social influence of collective norm, and upgrade the perceived influence of users in using it.

\section{$8 \quad$ Limitation and future studies}

This research presented three SNS factors that can influence the SNS use of university students. This study downsized the scale but did not consider the other influencing factors. The selection of survey objects also had a problem because of its small number. Although the reliability and small-scale analysis are good, the data cannot fully cover all aspects. Thus, future research must increase the number of survey objects and consider further influencing factors.

This research mainly took comprehensive SNS platforms as the objects and did not explore the SNS of specific majors, the major professional SNS used by university students, and the difference between their behaviors toward using comprehensive and professional SNS. Mobile SNS, such as WeChat, has become the mobile online SNS platform for users given the rapid development and popularization of mobile Internet and smart terminals. Future research must focus on the motive of users to participate in mobile SNS, the behavior of use, and the difference between mobile SNS behavior model and the traditional SNS behavior model.

Finally, this paper mainly focused on the factors of SNS use and lacks research on the online behavior of users. Future research should pay increased attention to the consistency of the online and offline behaviors of users, whether their behaviors online and offline are consistent, and whether the factors and influencing mechanisms can influence the consistency of user behaviors: the influence of collective behaviors, resonance efficacy, the motives of spreading malicious or negative information (i.e., rumors), the interrelation between governmental supervision policies, and the behaviors of SNS users.

\section{Acknowledgment}

This study was supported by the China Scholarship Council (201408420159) ; Humanities and Social Science research project in Hubei province department of education (13g587 and 14Z073) and Hubei province university excellent young and middle-aged scientific and technological innovation team plan (T201730). 


\section{References}

[1] S. A. Vannoy and P. Palvia.(2010). The social influence model of technology adoption. Communications of the ACM, 53(6): 149-153. https://doi.org/10.1145/1743546.1743585

[2] D. Sledgianowski and S. Kulviwat.(2009). Using social network sites: The effects of playfulness, critical mass and trust in a hedonic context. Journal of Computer Information Systems, 49(4): 74-83.

[3] C. M. K. Cheung, P. Y. Chiu, and M. K. O. Lee.(2011). Online social networks: Why do students use facebook? Computers in Human Behavior, 27(4): 1337-1343. https://doi.org/10.1016/j.chb.2010.07.028

[4] R. K. Baker and K. M. White.(2010). Predicting adolescents' use of social networking sites from an extended theory of planned behaviour perspective. Computer in Human Behavior, 26(6): 1591-1597. https://doi.org/10.1016/j.chb.2010.06.006

[5] O. Kwon and Y. Wen.(2010). An empirical study of the factors affecting social network service use. Computers in Human Behavior, 26(2): 254-263. https://doi.org/10.1016/j.chb. 2009.04.011

[6] E. Hargittai.(2008). Whose space? Differences among users and non-users of social network sites. Journal of Computer-Mediated Communication, 13(1): 276-297. https://doi.org/10.1111/j.1083-6101.2007.00396.x

[7] N. Ljepava, R. R. Orr, and S. Locke.(2013). Personality and social characteristics of facebook non-users and frequent users. Computer in Human Behavior, 29(6): 1602-1607. https://doi.org/10.1016/j.chb.2013.01.026

[8] C. M. K. Cheung and M. K. O. Lee.(2010). A theoretical model of intentional social action in online social networks. Decision Support Systems, 49(1): 24-30. https://doi.org/10.1016/j.dss.2009.12.006

[9] C. Xu, S. Ryan, V. Prybutok, and C. Wen.(2012). It is not for fun:An examination of social network site usage. Information \& Management, 49(5): 210-217. https://doi.org/10.1016/j.im.2012.05.001

[10] M. J. De Oliveira, M. K. Z. Huertas, and Z. Lin.(2015). Factors driving young users' engagement with Facebook: Evidence from Brazil. Computers in Human Behavior, 54(13): 54-61.

[11] P. Ifinedo.(2016). Applying uses and gratifications theory and social influence processes to understand students' pervasive adoption of social networking sites: Perspectives from the Americas. International Journal of Information Management, 36(2): 192-206. https://doi.org/10.1016/j.ijinfomgt.2015.11.007

[12] F. Davis.(1989). Perceived Usefulness, Perceived Ease of Use and User Acceptance of Information Technology. MIS Quarterly, 13(3): 319-340. https://doi.org/10.2307/249008

[13] K. Y. Lin and H. P. Lu.(2011). Why people use social networking sites: An empirical study integrating network externalities and motivation theory. Computers in Human Behavior, 27(3): 1152-1161. https://doi.org/10.1016/j.chb.2010.12.009

[14] T. Ryan and S. Xenos.(2011). Who uses Facebook? An investigation into the relationship between the Big Five, shyness, narcissism, loneliness, and Facebook usage. Computers in Human Behavior, 27(5): 1658-1664. https://doi.org/10.1016/j.chb.2011.02.004

[15] J. L. Skues, B. Williams, and L. Wise.(2012). The effects of personality traits, self-esteem, loneliness, and narcissism on Facebook use among university students. Computers in Human Behavior, 28(6): 2414-2419. https://doi.org/10.1016/j.chb.2012.07.012

[16] P. Sheldon.(2012). Profiling the non-users: Examination of life position indications, sensation seeking, shyness and loneliness among users and non-users of social network 
Paper-Influencing Factors of University Students' Use of Social Network Sites: An Empirical Analysis ...

sites. Computers in Human Behavior, 28(1): 1960-1965. https://doi.org/10.1016/j.chb.2012 .05 .016

[17] Y. E. Lee and A. N. Saharia, "The influence of self-concept improvement member loyalty to online communities: An empirical comparison between social networks and virtual world," in Proceeding of the 45th Hawaii international conference on system science, Maui,Hawaii, 2012, pp. 3550-3559. https://doi.org/10.1109/HICSS.2012.575

[18] D. A. de Vries and R. Kühne.(2015). Facebook and self-perception: Individual susceptibility to negative social comparison on Facebook. Personality and Individual Differences, 86(217-221. https://doi.org/10.1016/j.paid.2015.05.029

[19] R. Chen.(2013). Member use of social networking sites-An empirical examination. Decision Support Systems, 54(3): 1219-1227. https://doi.org/10.1016/j.dss.2012.10.028

[20] J. Bonds-Raacke and J. Raacke.(2010). Myspace and facebook: Identifying dimensions of uses and gratifications for friend networking sites. Individual Differences Research, 8(1): 27-33.

[21] Z. Tufekei.(2008). Grooming,gossip,Facebook and MySpace:What can we learn about these sites from those who won't assimilate. Information, Communication \& Society, 11(4): 544-564. https://doi.org/10.1080/13691180801999050

[22] F. T. McAndrew and H. S. Jeong.(2012). Who does what on Facebook? Age, sex, and relationship status as predictors of Facebook use. Computers in Human Behavior, 28(6): 2359-2365. https://doi.org/10.1016/j.chb.2012.07.007

[23] T. K. H. Chan, C. M. K. Cheung, N. Shi, and M. K. O. Lee.(2015). Gender differences in satisfaction with Facebook users. Industrial Management \& Data Systems, 115(1): 182206. https://doi.org/10.1108/IMDS-08-2014-0234

[24] P. Luarn and H. H. Lin.(2003). A customer loyalty model for e-service context. Journal of Electronic Commerce Research, 4(4): 156-167.

[25] L. C. Harris and M. M. H. Goode.(2004). The four levels of loyalty and the pivotal role of trust: A study of online service dynamics. Journal of Retailing, 80(2): 139-158. https://doi.org/10.1016/j.jretai.2004.04.002

[26] B. J. Babin, Y. K. Lee, and E. J. Kim.(2005). Modeling consumer satisfaction and word of-mouth: restaurant patronage in Korea. Journal of Services Marking, 19(3): 133-139. https://doi.org/10.1108/08876040510596803

[27] H. C. Chiu, Y. C. Hsieh, and Y. C. Li.(2005). Relationship marketing and consumer switching behavior. Journal of Business Research, 58(12): 1681-1689. https://doi.org/10.1016/j.jbusres.2004.11.005

[28] H. V. d. Heijden.(2004). User acceptance of hedonic information systems. MIS Quarterly, 28(4): 695-704. https://doi.org/10.2307/25148660

[29] F.D.Davis, R.P.Bagozzi, and P.R.Warshaw.(1992). Extrinsic and intrinsic motivation to use computers in the workplace Journal of Applied Social Psychology, 22(14): 1111-1132. https://doi.org/10.1111/j.1559-1816.1992.tb00945.x

[30] J. Moon and Y. Kim.(2001). Extending the TAM for a world-wide-web context. Information management, 38(1): 217-230. https://doi.org/10.1016/S0378-7206(00)00061-6

[31] D. L. Wang, L. L. Xu, and H. C. Chan, "Understanding users continuance of facebook:the role of general and special computer self efficacy," in Prodeedings of the international conference on information systems, 2008.

[32] J. N. Sheth and A. Parvatiyar.(1995). Relationship marketing in consumer markets: Antecedents and consequences Journal of Academy of Marketing Science, 23(4): 255-271. https://doi.org/10.1177/009207039502300405 
Paper-Influencing Factors of University Students' Use of Social Network Sites: An Empirical Analysis ...

[33] A. S. Dick and K. Basu.(1994). Customer loyalty: toward an integrated conceptual framework. Journal of Academy of Marketing Science, 22(2): 99-113. https://doi.org/10.1177/0092070394222001

[34] H. Haoming.(2012). Research on the motivation of college students to use SNS News World, 23(7): 211-213.

[35] A. Chaudhuri and M. B. Holbrook.(2001). The chain of effects from brand trust and brand affect to brand performance : the role of brand loyalty. Journal of Marketing, 65(2): 81-93. https://doi.org/10.1509/jmkg.65.2.81.18255

[36] H. H. Lin and Y. S. Wang.(2006). An examination of the determinants of customer loyalty in mobile commerce contexts. Information \& Management, 43(3): 271-282. https://doi.org/10.1016/j.im.2005.08.001

[37] T. Hu and W. J. Kettinger, "Why people continue to use social networking services: developing a comprehensive model," in Proceedings of the 2008 international conference on information systems, Paris, France, 2008.

[38] M. M. Al-Debei, E. Al-Lozi, and A. Papazafeiropoulou.(2013). Why people keep coming back to facebook: explaining and predicting continuance participation from an extended theory of planned behaviour perspective. Decision Support Systems, 30(4): 311-321. https://doi.org/10.1016/j.dss.2012.12.032

[39] R. Gu, L. B. Oh, and K. L. Wang, "Determinants of customer loyalty for social networking sites," in Exploring the grand challenges for next generation E-business:8th workshop on E-business, 2009, pp. 206-212.

[40] R. Gu, L.-B. OH, and K. Wang.(2013). Empirical study on the effect of perceived value and social influence on user loyalty for social networking sites. Journal of Information resources management, 3(1): 10-21.

[41] D. H. Shin and W. Y. Kim.(2008). Applying the technology acceptance model and flow theory to Cyworld user behavior. CyberPsychology \& Behavior, 11(3): 378-384. https://doi.org/10.1089/cpb.2007.0117

[42] G. S. Leng, S. Lada, and M. Z. Muhammad.(2011). An exploration of social networking sites (SNS) adoption in malaysia using Technology Acceptance Model (ATM) and intrinsic motication. Journal of Internet Banking and Commerce, 16(2): 1-27.

[43] J. C. M. R. Pinho and A. M. Soares.(2011). Examining the technology acceptance model in the adoption of social networks. Journal of Research in Interactive Marketing, 5(2/3): 116-129. https://doi.org/10.1108/17505931111187767

[44] y. Zhou and 1. Wang.(2011). Research on the influence factors of university students use the social network service. E-education research, 223(11): 41-45.

[45] R. Chen.(2013). Member use of social netwoeking sites-An empirical examination. Decision Support Systems, 54(1): 1219-1227. https://doi.org/10.1016/j.dss.2012.10.028

[46] S. C. Chen, D. C. Yen, and M. I. Hwang.(2012). Factors influencing the continuance intention to the usage of web 2.0: an empirical study. Computer in Human Behavior, 28(2): 933-941. https://doi.org/10.1016/j.chb.2011.12.014

[47] Nunnally.J, Psychometric Theory. New York,NY, 1978.

[48] M. S. Garver and J. T. Mentzer.(1999). Logistics research method: employing structural equation modeling to test for construct validity. Journal of Business Logistics, 20(1): 3358 .

[49] Field.A, Discovering Statistics Using SPSS. London: Sage, 2005.

[50] K. B. Ooi, V. Arumugam, P. L. Teh, and A. Y. L. Chong.(2008). TQM practice and its association with production workers. Industrial Management \& Data Systems, 108(7): 909-927. https://doi.org/10.1108/02635570810897991

[51] S. Chatterjee and B. Price, Regression analysis by example. New York: Wiley, 1991. 
Paper-Influencing Factors of University Students' Use of Social Network Sites: An Empirical Analysis ...

[52] K. B. Ooi, N. A. Bakar, V. Arumugam, L. Vellapan, and A. K. Y. Loke.(2007). Does TQM influence employees job satisfaction? An empirical case analysis. International journal of Quality \& Reliability Management, 24(1): 62-77. https://doi.org/10.1108/02656 710710720330

[53] R. Gu.(2011). Determinants of customer loyalty for social networking sites. Lecture notes in business information processing, 52(6): 206-212.

[54] Y. Lifang and J. Zhiyu.(2011). The research on the motivation of college student use SNS. Heihe Journal, 173(12): 117-118.

[55] I. Cho, J. K. Kim, H. Park, and S. M. Lee.(2014). Motivations of Facebook Places and store atmosphere as moderator. Industrial Management \& Data Systems, 114(9): 13601377. https://doi.org/10.1108/IMDS-07-2014-0218

\section{Authors}

Liqiong Liu is a doctoral student at the School of Information Management, Wuhan University, and an associate professor at the School of Business Administration, Wuhan Business University, Wuhan, 430056, China.

Liyi Zhang is a professor at the School of Information Management, Wuhan University, Wuhan, 430072, China.

Pinghao YE is an associate professor at the School of Information Engineering, Wuhan Business University, Wuhan, 430056, China.

Qihua Liu is an associate professor at the School of Information Management, Jiangxi University of Finance and Economics, Nanchang, 330013, China.

Article submitted 07 February 2018. Final acceptance 23 February 2018. Final version published as submitted by the author. 